\title{
Method of Estimating Air-Liquid Interfacial Area Using Soil Characteristics Curve
}

\author{
A.H.M. Faisal Anwar* and Uichiro Matsubayashi** \\ 水分特性曲線を用いた気一液境界面の面積の推定法
}

\author{
A.H.M. ファイサル アンワル*・松林宇一郎**
}

\begin{abstract}
Air-liquid interfacial area $\left(a_{i}\right)$ is an important parameter in the subsurface hydrology that describes the pore scale distribution of air and liquid inside the porous media. In order to quantify this parameter, a theoretical model using soil characteristics $(\psi-\theta)$ curve was developed by introducing a term "hydraulic radius" for the pores inside the medium. This term diminishes the effect of any shape of the pore. The derivation becomes a simple expression which needs only drainage soil characteristics curve. In this study, $\psi-\theta$ curves were developed experimentally for three glass beads media $(0.25 \mathrm{~mm}, 0.50$ $\mathrm{mm}$ and $0.75 \mathrm{~mm}$ ) and the theoretical method was applied successfully to estimate the parameter, $a_{i}$ in these different porous media. Results obtained by this method follow the general concept of decreasing $a_{i}$ with increasing liquid saturation. They also show that the $a_{i}$ is increasing with decreasing grain size, which supports the frequency distribution of the pore sizes inside the porous media. Estimated air-liquid interfacial area was also compared with the results obtained by an experimental technique using surfactant mass extraction. Comparison of the results shows that the interfacial area determined by this theoretical method provides reasonable estimation. Finally, the method was applied to a sand mixture $\left(d_{50}=0.25 \mathrm{~mm}\right)$ to estimate the air-liquid interfacial area and was compared with the experimental results of interfacial tracer technique as described by Kim et al., (1997). Results found by comparing $a_{i}$ of solid surface area at zero saturation revealed that the theoretical method provides reasonable estimation of $a_{i}$ than the interfacial tracer technique.
\end{abstract}

* Department of Civil Engineering, Nagoya University,

** Research Center for Advanced Waste and Emission Management, Nagoya University, 
Key Words: porous media, interfacial area, $\psi-\theta$ curve, unsaturated, pore diameter.

\section{要 旨}

気一液境界面の面積 $\left(a_{i}\right)$ は, 多孔体中の気体と液体の間隙スケール分布を表し, 地下水 文学において，重要なパラメータである。このパラメー夕量を求めるために，多孔体の間 隙に「径深」の項を導入することにより，水分特性曲線 ( $\psi-\theta$ 曲線)を用いた理論モデル が提案されている。これにより，間隙の形状効果を減少させることができる。この誘導式 は, 排水過程の水分特性曲線のみで簡単に表現できる。

本研究では, 粒径の異なる 3 種類のガラスビーズ (粒径: $0.25 \mathrm{~mm}, 0.50 \mathrm{~mm}$ 及び $0.75 \mathrm{~mm}$ ) を用いて実験を行い, 水分特性曲線 ( $\psi-\theta$ 曲線)を作成し，理論モデルを適用した結果， 本研究で提案した理論モデルがパラメータ $a_{i}$ の推定にうまく適用された。

試験結果より, 気一液境界面の面積 $\left(a_{i}\right)$ は, 飽和度の増加に伴って減少する。又, 気一 液境界面の面積 $\left(a_{i}\right)$ は，ガラスビーズの粒径の減少に伴って増大する。このことは，ガラ スビーズの粒径の減少に伴って, 多孔体中の間陌の度数分布が増大することを示している。 又, 推定された気一液境界面の面積 $\left(a_{i}\right)$ を, surfactant mass extraction 試験により得られ た值と比較し, 検証を加えた結果, 気一液境界面の面積 $\left(a_{i}\right)$ は, 理論モデルによって得ら れた推定值と比べ，妥当であると言える。

最後に, 本研究で提案した方法を砂 (平均粒径 : $0.25 \mathrm{~mm}$ )に適用し, 気一液境界面の面 積 $\left(a_{i}\right)$ を推定し, Kim ら (1997)によるInterfacial tracer 法の結果と比較した。その結果, 飽和度 0 の時, 気一液境界面の面積 $\left(a_{i}\right)$ が多孔体中の固体表面積であることを示してお り, 本研究で提案した方法は, Interfacial tracer法と比べてより良い推定法であると考える。

キーワード : 多孔体, 界面の面積, $\psi-\theta$ 曲線, 不飽和, 間隙径

\section{Introduction}

A considerable research had been conducted in the last few decades in order to understand the soil-water retention characteristics in unsaturated porous media (Brooks and Corey, 1966; Campbell, 1974; Van Genuchten, 1980; Lenhard and Parker, 1987; Tanhueco, 1993; Hofstee et al., 1997). Soils may temporarily become saturated due to some irrigation or rainfall (aqueous phase liquid) events of sufficient intensity and duration or due to leakage or spillage of non-aqueous phase liquids (NAPLs) from industrial sources. Surface soils may prevail saturated for some time during the infiltration and redistribution of these liquids inside the porous media. As this process proceeds, air starts to enter inside the soil and system becomes un. saturated where air and liquid (water or NAPL) coexist as the two separate immiscible fluid phases. Pore scale distribution of these fluids depends on the physical and chemical properties of the solute and the media. Interfaces between these phases (i.e. air/liquid) play a significant role in many flow and transport processes, especially during the characterization and the remediation of the volatile organic contaminants in the vadose zone where NAPL-vapor phase mass 
transfer is important (Barida and Ong, 1998; Cho and Jaffe, 1990; Imhoff and Jaffe, 1994; Wilkins et al., 1995). Air-liquid interfacial area $\left(a_{i}\right)$ quantifies these interfaces and describes the pore scale distribution of air and liquid inside the unsaturated porous media.

A number of theoretical approaches had been reported in the literature in order to quantify the fluid-fluid interfacial area which include: thermodynamic treatment on pressure-saturation relationship (Bradford and Leij, 1997), pore network model (Reeves and Celia, 1996; Celia et al., 1998; Kawanishi et al., 1998) and simplification of pore geometry (Skopp, 1985; Miller et al., 1990; Cary, 1994;). However, thermodynamic and pore network approaches describe the interfacial area considering the complex network of the interconnected pores. On the other hand, models derived by simplifying pore geometry are coupled with Campbell's fitting parameter (Campbell, 1974) which produced only some general information (Cary, 1994) about the fluid-fluid interfacial area but failed to show any realistic information (Skopp, 1985), especially with respect to the soil texture. Verifications or comparisons of most of these models are still far away with that of experimental results because of experimentally inaccessibility to this parameter for a long time.

Successful experiments were performed in order to estimate $a_{i}$ quantitatively in last few years by two methods considering the surfactant adsorption between the phases (Karkare and fort, 1996; Kim et al., 1997; Saripalli et al., 1997). First method describes the migration of the water by inducing a water-insoluble surfactant (1-tetradecanol) under static condition and $a_{i}$ was calculated from the critical surfactant concentration (number of molecules accumulated at the interface) that is needed to initiate the water movement and the average molecular area of the surfactant. Second method describes the adsorption of surfactant at the air-water interface under dynamic condition and $a_{i}$ was calculated from the retardation factors obtained from the breakthrough curves (BTCs) for surface reactive and non-reactive tracers respectively for varieties of water saturation. Recently, a new experimental technique has been developed in our laboratory considering the extraction of surfactant mass from the unsaturated soil water and analysis by two-phase titration to estimate air-water interfacial area for different water saturation using surfactant adsorption concept.

In this paper, a theoretical model is developed to estimate the air-liquid interfacial area from soil characteristics $(\psi-\theta)$ curve by introducing the term "hydraulic radius" of the pore inside the medium. The derivation becomes a simple expression that needs only the drainage soil characteristics curve. The value of $a_{i}$ was estimated using measured $a_{i}$ curve for three glass beads media and was compared with the experimental results obtained from surfactant mass extraction technique. Air-liquid interfacial area was also calculated for a sand mixture and compared with the area estimated by interfacial tracer technique as described by Kim et al., (1997).

\section{Method Development}

A porous medium is composed of solid matrix and a numerous number of interconnected pores of various sizes and shapes. During the wetting process in the porous media, first the smaller pores begin to fill up and then the larger ones as the liquid content increases. During unsaturation or drainage process, system becomes reverse. As the drainage proceeds, from larger to smaller pores are drained leaving the pore walls covered with a thin liquid film. This provides an easy access to calculate the air-liquid interfacial area $\left(a_{i}\right)$ from the drainage soil characteristics or suction head-moisture content $(\psi-\theta)$ curve.

The simplest model for describing the pore 
structure may be the capillary bundle tube which consists of a series of cylindrical capillary tubes of different diameters with equal lengths (Dullien, 1979). But in reality, the capillary pores can be of any shapes. In order to avoid these discrepancies on pore shape, a term "hydraulic radius, R" is introduced here for the pore, which is the ratio between the cross-sectional area of pore of any shape to the wetted perimeter.

Let us assume a pore of cross-sectional area, $A_{p}\left(\mathrm{~cm}^{2}\right)$ filled up by a liquid with surface tension $\sigma(\mathrm{dyn} / \mathrm{cm})$ to a height of $\psi(\mathrm{cm})$ due to the capillary action and is shown in Fig. 1. As the meniscus touches along the line of contact between the liquid and the pore wall, i.e. the perimeter, $P(\mathrm{~cm})$ of the wetted pore, the total upward force on the liquid is $P \sigma \cos \alpha$, where $\alpha$ is the contact angle usually assumed as zero for the water. It is this force which supports the weight of the column of liquid up to height $\psi$ plus the weight of water in the meniscus itself. The total weight of liquid is $\left(A_{p} \psi+V_{m}\right) \rho g$, where, $V_{m}$ is the volume of water in the meniscus and $\rho$ is the density of the liquid.

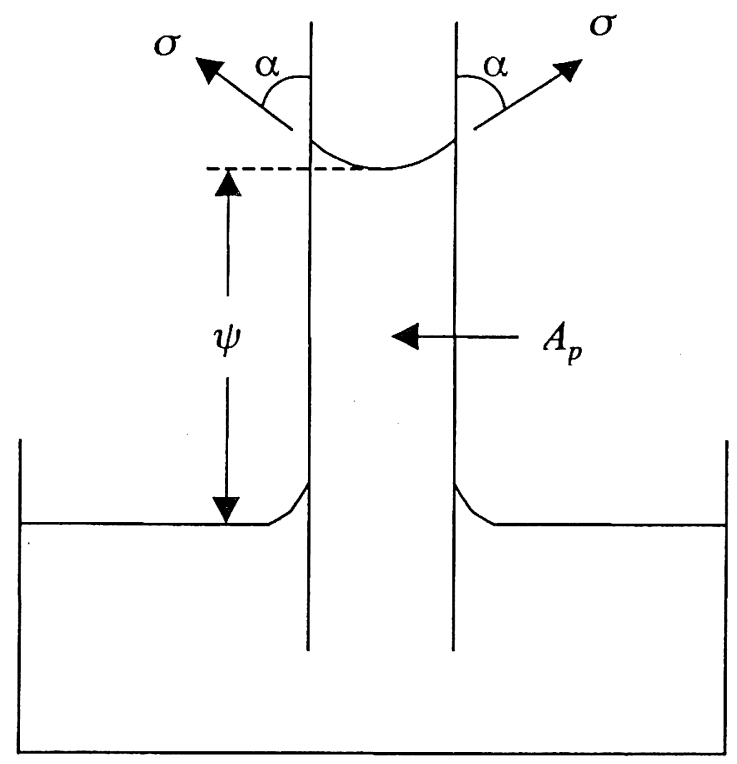

Fig. 1 Rise of liquid in a typical pore due to capillary action.
At equilibrium, the two forces must be balanced, therefore,

$$
P \sigma=\left(A_{P} \psi+V_{m}\right) \rho g
$$

Volume of liquid in the meniscus is usually negligible, expressing equation (1) in terms of hydraulic radius, $R$ :

$$
R=\frac{A_{P}}{P}=\frac{\sigma}{\psi \rho g}
$$

Here $R$ is expressed where $\psi$ is a function of volumetric liquid content, $\theta_{l}$. In order to derive the expression for air-liquid interfacial area hydraulic radius should be expressed for the reverse side, i.e. gas or air side,

$$
R=f\left(\psi\left(\theta_{g}\right)\right)
$$

where, $\psi$ is a function of volumetric gas content, $\theta_{g}$.

After drainage, for a specific liquid content, $\theta_{1}$, the cross-section of the medium with liquid filled pores for typical pores with circular cross section is shown in Fig.2 (a) where all the empty pores are assumed to be lined with a liquid film. In Fig. 2(b), Gas (or air) volumes and liquid volumes are presented in total void spaces, which can be expressed by:

$$
\begin{aligned}
& V_{s}=\theta_{g^{\prime}} V_{t} \\
& V_{l}=\theta_{l} V_{t} \\
& V_{v}=\phi_{t} V_{t}
\end{aligned}
$$

where, $V_{b}, V_{l}$ and $V_{v}$ are the gas, liquid and void volume respectively $\left(\mathrm{cm}^{3}\right)$ while $V_{t}$ is the total volume of the porous media $\left(\mathrm{cm}^{3}\right), \theta_{l}$ and $\theta_{g}$ are the volumetric liquid and gas content respectively $\left(\mathrm{cm}^{3} / \mathrm{cm}^{3}\right)$ while $\phi_{t}$ is the total porosity of the medium. However, these expressions are true for any shape of the pores in cross section.

Assuming a unit cross sectional area of the medium, the number of pores, $d N$, for same size and shape for each increment of gas content, $d \theta_{g^{\prime}}$ can be expressed by:

$$
d N=\frac{d \theta_{r}}{A_{P}}
$$




\section{Liquid filled pores}

(a)

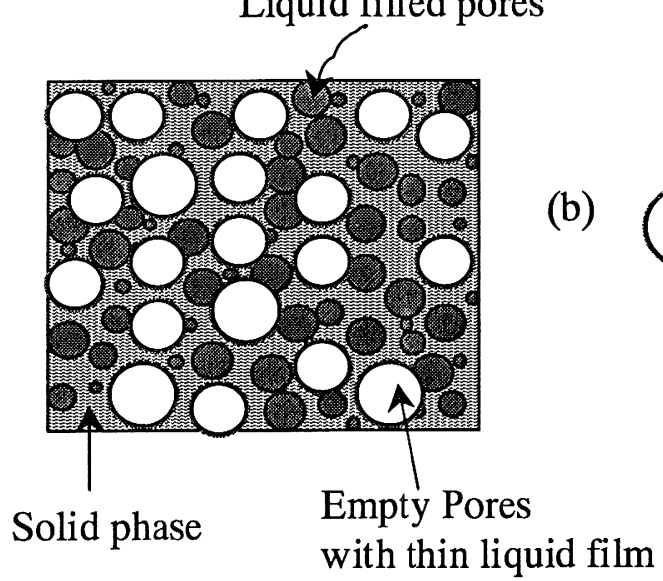

Fig. 2 (a). A typical Cross section of unsaturated porous medium with liquid filled pores of circular cross section.

(b). Gas and liquid volumes are shown in total void spaces for the same section.

For a single drained pore with volume, $V_{1}$ and inside surface area, $a_{s}$, hydraulic radius of the pore, $R$ can be expressed by:

$$
R=\frac{V_{1}}{a_{s}}
$$

Equation (8) may be converted to $d N$ number of pores with same size and shape for each increment of gas content, $d \theta_{s^{\prime}}$ as:

$$
R=\frac{V_{t} d \theta_{s} / d N}{d A_{s} / d N}
$$

where, $d A_{s}$ is the surface area corresponding to the incremental gas content $d \theta_{g}$.

Rearrenging equation (9):

$$
d A_{s}=\frac{d \theta_{s}}{R} V_{t}
$$

Specific air (or gas)-liquid interfacial area, $a_{i}$ is defined as the ratio of total interfacial area between air and liquid, $A_{s}$ to the volume of total porous medium that can be expressed from equation (10) as:

$$
a_{i}=\frac{A_{s}}{V_{t}}=\frac{\int_{(\Lambda s)} d A_{s}}{V_{t}}=\int_{0}^{\theta g} \frac{d \theta_{g^{\prime}}}{R}
$$

where, $R$ is a function of volumetric gas content, $\theta_{g}$.

Combining equation (2), (3) and (11), expression for $a_{i}$ becomes:

$$
a_{i}=\frac{\rho \mathrm{g}}{\sigma} \int_{0}^{\theta g} \psi d \theta_{g}
$$

where, $\psi$ is the suction head of liquid and function of volumetric gas content, $\theta_{g}$. Thus equation (12) needs only $\psi-\theta$ curve of the medium to calculate the air (or gas)-liquid interfacial area.

\section{Establishment of $\psi-\theta$ curve}

\subsection{Materials used}

Three glass beads (supplied by Toshiba Barotini Company Ltd., Japan) of different sizes were chosen as the porous media to develop the $\psi-\theta$ curve. Different properties of the media are shown in Table 1. Normal tap water was used for the experiments.

\subsection{Experiments}

The experimental column was comprised of 15 pieces of PVC rings of $5 \mathrm{~cm}$ length and $10 \mathrm{~cm}$ diameter and a bottom section of same diameter. The bottom section was consisted of a perforated plate together with a stainless steel mesh on it and an outlet, which allowed water flow easily through it but retained the glass beads. The column was made by stacking the PVC rings 
Table 1 Properties of the porous media

\begin{tabular}{ccccc}
\hline Porous & Range of & Average & Bulk & Porosity \\
medium & diameter & diameter & density & \\
& $(\mu \mathrm{m})$ & $\mathrm{d}_{50}(\mathrm{~mm})$ & $\rho_{\mathrm{b}}\left(\mathrm{g} / \mathrm{cm}^{3}\right)$ & $\phi_{\mathrm{t}}$ \\
\hline Glass bead & $212-300$ & 0.25 & 1.55 & 0.387 \\
Glass bead & $425-600$ & 0.50 & 1.53 & 0.373 \\
Glass bead & $600-850$ & 0.75 & 1.51 & 0.368 \\
\hline
\end{tabular}

and the two adjacent rings were joined carefully by adhesive water resistant tape and kept standing on the bottom section as shown in Fig. 3.

System constructed in this way was kept filled with water overnight and found no leakage in the joints. The column, initially filled with water, was packed successively with the glass beads in small increments and tapped at the bottom. The length of the soil column filled in this process was around $72 \mathrm{~cm}$. This procedure ensured the elimination of any trapped air and layer formation during the packing process. The column was kept saturated for 1 hour and the outlet tank was brought down and kept the water level of the outlet at the same level of the bottom of the soil column. The column was kept like this for 24 hours in order to make the system equilibrium. After establishing equilibrium in the system, the column was dismantled and the weights of the wet soil were measured for each ring. The wet soil was oven dried at $110^{\circ} \mathrm{C}$ for 24 hours and the moisture content was measured gravimetrically for each ring. Finally, moisture contents obtained by this method were plotted with corresponding suction heads and are shown in Fig. 4 for different glass beads media.

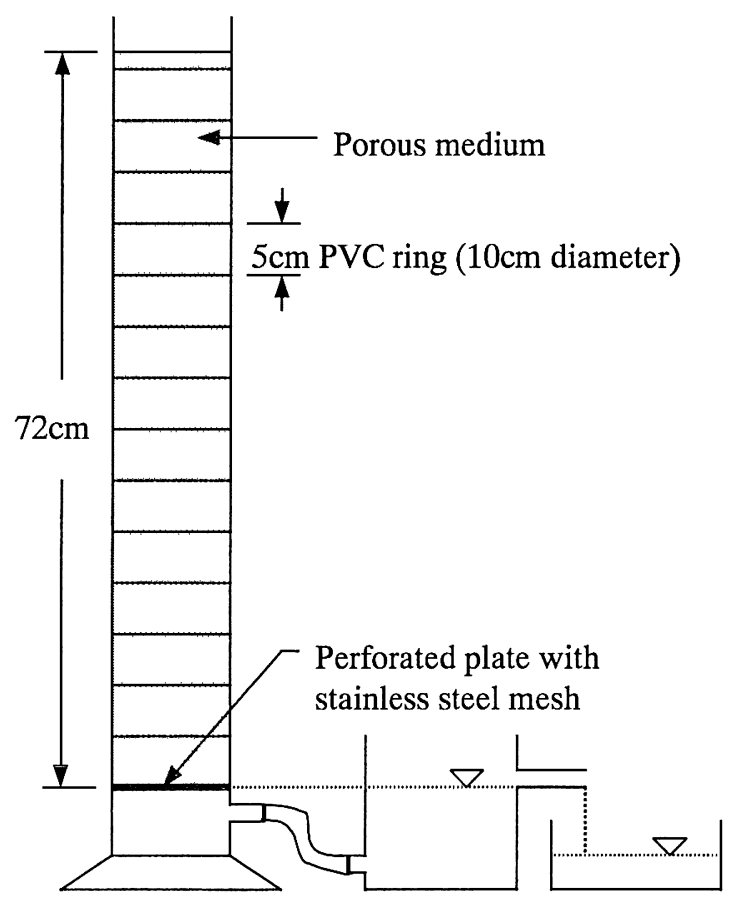

Fig. 3 Experimental set up used to develop $\psi-\theta$ curve.

\section{Discussion}

\subsection{Application of the Theoretical Method}

$\psi-\theta$ curves established for three glass beads media were taken to apply this method. At first, $\psi-\theta$ curve was subdivided into small gas content increments of $d \theta_{g}=0.005 \mathrm{~cm}^{3} / \mathrm{cm}^{3}$ and corresponding suction head $(d \psi)$ was lo- 


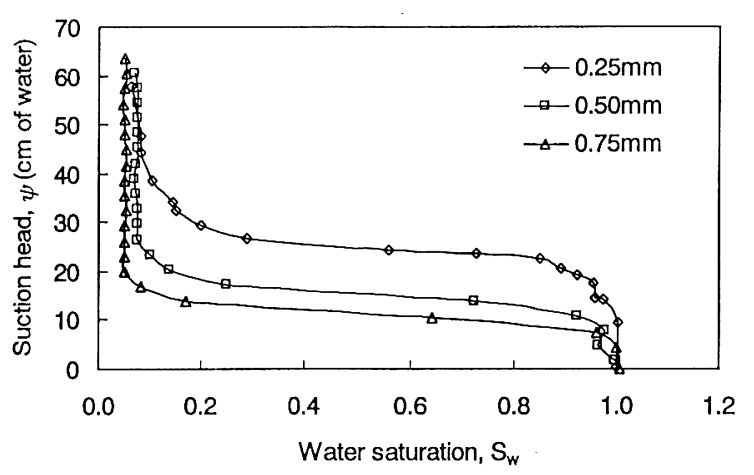

Fig. 4 Measured $\psi-\theta$ curve with water for three glass beads media.

cated in the curve. Air-water interfacial area was estimated for different water content using equation (12) and shown in Fig. 5 for three glass beads media.

Most of the pressure saturation relationships only describe the region where both fluids are continuous. It does not give any information below the residual saturation. Thus the interfacial area calculated using equation (12) is strictly valid only for variable region of saturation. Miller et al., (1990) cited from literature that the interfacial area must pass through a maximum and return to a zero value as saturation tends to zero. It may be explained as the saturation increases from zero, interfacial area should also start from zero and pass through a maximum value and return to zero at the saturated condition.

Results obtained from different glass beads media show that interfacial area increases with decreasing water saturation up to residual condition. This provides the general behavior of the system that available interfacial area should decrease with increasing saturation. However, quantitative behavior of interfacial area in the residual zone of saturation has not yet been investigated (Miller, et al., 1990).

Figure 5 also shows that estimated interfacial area decreases with increasing grain size, which supports the frequency distribution of the

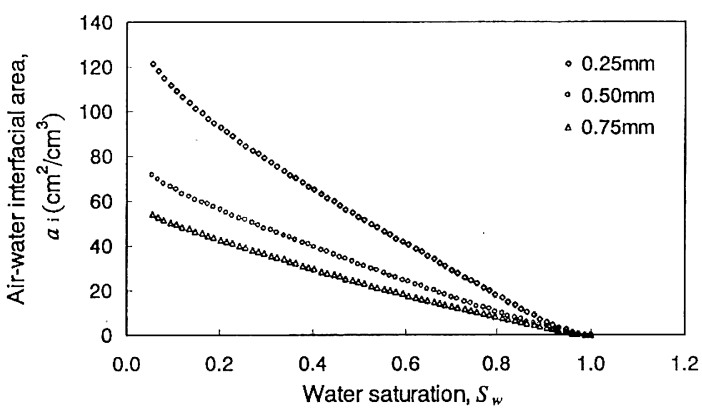

Fig. 5 Calculated air(or gas)-liquid interfacial area using equation (12) with water saturation for three glass beads media.

pores inside the porous media. Assuming circular cross sectional area for the pores inside, the pore diameter, $D$ is calculated as $D=4 \sigma / \psi \rho_{g}$ and the number of pores are estimated using equation (7). Frequencies of the same diameter pores inside each medium are presented in Fig. 6 which shows that bigger grain size media have larger diameter pores with lesser frequencies. As the interfacial areas calculated here is the summation of the surface areas of all drained pores, small grain size media gave bigger interfacial areas because of high frequencies.

According to equation (12), air-liquid interfacial area is related with $\rho \psi / \sigma$ where $\rho / \sigma$ is the chemical property of the liquid (solute). Again, capillary pressure or suction head $(\psi)$ is inversely proportional to $\rho / \sigma$. Thus the term $\rho \psi / \sigma$ in equation (12) would be the same for a particular porous media, whatever may be the liquid used to develop $\psi-\rho$ curve. Thus air (or gas)-liquid interfacial area for the porous media calculated by equation (12) may be true for any air-liquid system present in the media.

\subsection{Comparison of the Theoretical Method with the Experimental Results \\ 4.2.1 Comparison with the Technique of Es- timating $a_{i}$ using Surfactant Mass Extraction}

Recently, a new experimental technique has been demonstrated in our laboratory to estimate 

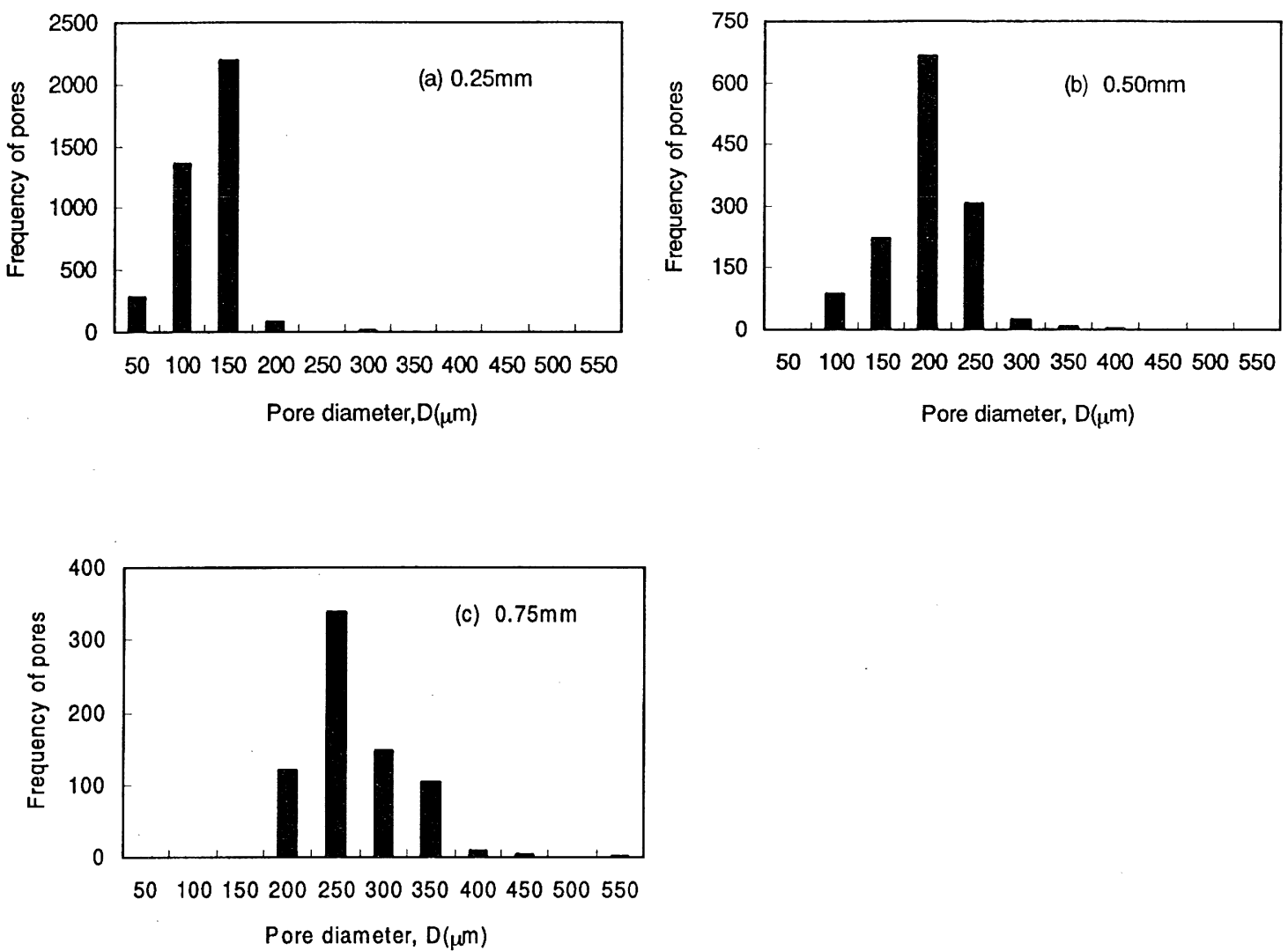

Fig. 6 Frequency distribution of pore sizes in different glass beads media assuming the circular cross section of the pores.

air-liquid interfacial area in unsaturated porous media using surfactant adsorption concept. In this method, surfactant mass from the unsaturated soil water was extracted and analyzed by two-phase titration (Brewer, 1972). A brief description of the method is discussed here for the convenience of the reader:

\section{Theoretical Basis}

The basic concept of this method was based on the strong tendency of surfactant monomers to accumulate at the interfacial regions such as, solid/liquid, liquid/liquid or air/liquid interfaces in an oriented fashion. In an unsaturated flow system with surfactant solution of concentration $C_{s}\left(C_{s}<C M C\right.$, Critical Micellar Concentration), some surfactant monomers are usual- ly remained in liquid phase while some others are adsorbed in solid/liquid interface and air/liquid interface. Total surfactant mass per unit volume, $M_{T}\left(\mathrm{~mol} / \mathrm{cm}^{3}\right)$ in such system can be expressed as:

$$
M_{T}=M_{S}+M_{I}+M_{L}
$$

where, $M_{S}$ and $M_{I}$ are the surfactant mass adsorbed per unit volume at solid/liquid and air/liquid interface respectively $\left(\mathrm{mol} / \mathrm{cm}^{3}\right)$ and $M_{L}$ is the surfactant mass per unit volume $\left(\mathrm{mol} / \mathrm{cm}^{3}\right)$ in the bulk liquid phase.

In order to estimate surfactant mass adsorbed in solid phase, aqueous transport of surfactant solution in saturated porous medium (i.e., no air/liquid interface) can be modeled by one-dimensional transport equation for conservative chemicals as (Bear and Verruijt, 1987): 


$$
\begin{aligned}
\phi_{t} & =\frac{\partial C_{s}}{\partial t} \\
& =D_{w} \phi_{t} \frac{\partial^{2} C_{s}}{\partial z^{2}}-\phi_{t} v_{w} \frac{\partial C_{s}}{\partial z}-\rho_{b} k_{d} \frac{\partial C_{s}}{\partial t}
\end{aligned}
$$

where, $v_{w}$ is pore water velocity $(\mathrm{cm} / \mathrm{min}), D_{w}$ is the hydrodynamic dispersion coefficient $\left(\mathrm{cm}^{2} / \mathrm{min}\right), C_{s}$ is the surfactant concentration in the bulk liquid phase $\left(\mathrm{mol} / \mathrm{cm}^{3}\right), \phi_{t}$ is the porosity, $\rho_{b}$ is the bulk density of the medium $\left(\mathrm{g} / \mathrm{cm}^{3}\right), k_{d}\left(k_{d}=0\right.$ for non adsorptive and $k_{d}>0$ for adsorptive solute) is the linear distribution coefficient for surfactant adsorption on solid phase $\left(\mathrm{cm}^{3} / \mathrm{g}\right)$. Rearranging equation (14):

$$
R_{t} \frac{\partial C_{s}}{\partial t}=D_{u} \frac{\partial C_{s}}{\partial z^{2}}-v_{u} \frac{\partial C_{s}}{\partial z}
$$

where, $R_{t}$ is the dimensionless retardation factor expressed by:

$$
R_{t}=1+\frac{\rho_{b} k_{d}}{\phi_{t}}
$$

The retardation factor, $R_{l}$. can be calculated by comparing the BTCs for reactive and non-reactive solutes that are obtained from miscible displacement experiments. Thus, distribution coefficient $k_{d}$ can be estimated and converted to the amount of surfactant adsorbed onto the solid matrix, $M_{S}$.

In the air/liquid interface, it is usually assumed with practical significance that surfactant molecules culminate a monolayer coverage and each molecule occupies a known molecular area (Saripalli et al., 1997). This provides the opportunity to estimate the surfactant mass adsorbed at the air-water interface. In an unsaturated soil water system, the adsorbed amount of surfactant at the air/water interface per unit volume of porous medium can be expressed as:

$$
M_{I}=\Gamma a_{i}
$$

where, $\Gamma$ is the surface (excess) concentration of the surfactant or the number of molecules adsorbed per unit area $\left(\mathrm{mol} / \mathrm{cm}^{2}\right)$ at the air-water interface and $a_{i}$ is the air-water interfacial area per unit volume of porous medium $\left(\mathrm{cm}^{2} / \mathrm{cm}^{3}\right)$. Direct measurement of surface excess concentration at the air-water interface is usually not feasible. It is generally determined by Gibbs adsorption equation using the relationship between surface tension, $\sigma$ and the bulk surfactant concentration, $C_{s}$ (Davies and Rideal, 1961; Rosen, 1989) as:

$$
\partial \sigma=-R T \Gamma \partial\left(\ln C_{s}\right)
$$

where, $\sigma$ is the surface tension $(\mathrm{dyn} / \mathrm{cm}), T$ is absolute temperature $\left({ }^{0} \mathrm{~K}\right)$, and $R$ is the ideal gas constant.

Total surfactant mass $\left(M_{\tau}\right)$ in the unsaturated soil water and the surfactant concentration in the bulk liquid phase $\left(C_{s}\right)$ may be obtained by two-phase titration technique (Brewer, 1972). In this method anionic surfactant is titrated by a cationic surfactant in presence of a solvent and a color indicator. Thus all the parameters are known to estimate air-water interfacial area in unsaturated porous media. Expression for air-water interfacial area $\left(\alpha_{i}\right)$ can be written from equation (13) and (17) for varieties of water saturation, $S_{w}$ as:

$$
\alpha_{i}=\frac{M_{T}-M_{S}-\theta_{w} C_{s}}{\Gamma}
$$

where, $\theta_{w}$ is the volumetric water content $\left(\mathrm{cm}^{3} / \mathrm{cm}^{3}\right)$ usually measured gravimetrically and $\theta_{u} C_{s}$ is the surfactant mass in liquid phase (i.e., $M_{L}=\theta_{w} C_{s}$ ) for different water content.

\section{Experimental Process}

A column composed of several stainless steel rings $(9.6 \mathrm{~cm}$ diameter and $3 \mathrm{~cm}$ length each) was used to carry out the saturated/unsaturated experiments in three glass beads media (same as this study) as shown in Fig. 7. An anionic surfactant - sodium dodecylbenzene sulfonate (SDBS) and sodium chloride $(\mathrm{NaCl})$ was used as the surface reactive and nonreactive tracers respectively. Surfactant mass adsorption onto solid phase was determined through miscible displacement experiments under water saturated conditions (i.e., no air/liquid inter 
face). $\mathrm{NaCl}$ concentration was determined by specific conductivity (SC) of the solution, which was measured with the help of the electrodes and SC meter (Matsubayashi, et al., 1995) and the SDBS concentration of the collected samples was analyzed using UV spectrophotometer (IUV-1200, Iuchi Science Co. Ltd., Japan) set at $235 \mathrm{~nm}$ wavelength. The breakthrough curves (BTCs) were plotted for this condition with SDBS and $\mathrm{NaCl}$ respectively to estimate the retardation factor $\left(R_{t}\right)$.

The medium was made unsaturated step by step with recycled surfactant solution (i.e., way I in Fig. 7 is closed) from saturated condition to achieve steady and homogeneous surfactant concentration in the liquid phase by allowing the surfactant monomers to be adsorbed at the air-water interface in a regular fashion. Step by step reduction of flow rate and keeping each flow rate for several hours ensured to form a stable air-liquid interface and thus the air-liquid interfacial area inside the system. This process also helped to obtain the homogeneous surfactant concentration in the aqueous phase in each step of flow rate. When the column attained this equilib-

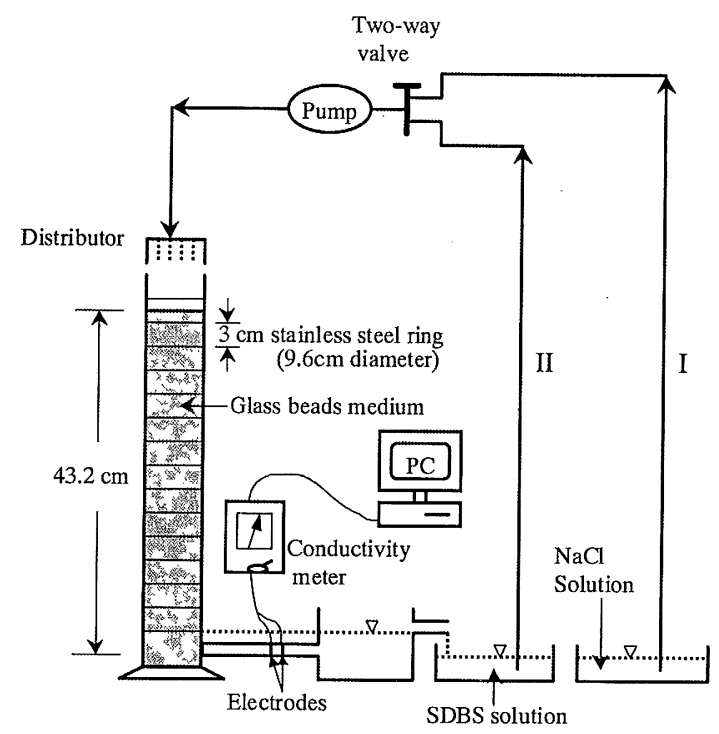

Fig. 7 Scheme of the experimental setup to estimate air-liquid interfacial area. rium condition at the end of the last flow rate (very small), the rings were dismantled and total surfactant mass $\left(M_{T}\right)$ from each ring was extracted and analyzed by two-phase Hyamine 1622 titration method (Brewer, 1972). The surfactant concentration in the bulk aqueous phase (sampled at the column outlet at the end of the experiment) $\left(C_{s}\right)$ was also determined by the same technique and was converted to $\mathrm{ML}$. for specific water content (i.e., $M_{L}=\theta_{w} C_{s}$ ). The number of surfactant monomers adsorbed on the air-water interface per unit area was determined by Gibbs isotherm. Gibbs adsorption equation (equation 18) was developed by measuring surface tension of surfactant solution for different concentration at constant temperature and surface (excess) concentration of surfactant $(\Gamma)$ was evaluated from the fitted equation. Finally, air-water interfacial area was estimated from the amount of SDBS on the air-water interface $\left(M_{l}\right)$ divided by the number of SDBS monomers per unit area $(\Gamma)$.

\section{Results and Comparison}

Surface tension data were plotted with different surfactant concentration to develop the equation for Gibbs adsorption (equation 18) and surface (excess) concentration of the sur. factant $(\Gamma)$ was calculated from the fitted equation, which was equal to $2.87 \times 10^{-10}\left(\mathrm{~mol} / \mathrm{cm}^{2}\right)$.

Breakthrough curves obtained for SDBS and $\mathrm{NaCl}$ under water saturated conditions in column miscible displacement experiments were compared and retardation factors $\left(R_{t}\right)$ were calculated as unity for all the glass beads media. This provides the information (equation 16) about the surfactant adsorption onto the solid phase (i.e., $k_{d}=0$ ). Thus, the surfactant mass adsorbed onto solid for glass beads surfaces was taken as zero (i.e., $M_{S}=0$ ), which is in an agreement with the results obtained by Saripalli, et al., (1997). Total surfactant mass in un- 
saturated soil water $\left(M_{T}\right)$ and surfactant mass in liquid phase $\left(M_{L}\right)$ was determined by two phase Hyamine titration method (Brewer, 1972). Now, all the required parameters are in hand to estimate the air-liquid interfacial area according to equation (19). Thus the air-liquid interfacial area estimated by this surfactant mass extraction technique was also found decreasing with increasing liquid saturation and grain sizes.

Results obtained by this experimental technique (equation 19) is presented together with the results found by the theoretical model (equation 12) for different porous media for the sake of comparison and are shown in Fig. 8 . Results shown in Fig. 8 revealed that the area estimated by theoretical method somehow show overestimation, especially in the lower saturation zone. This is not unlikely, because the
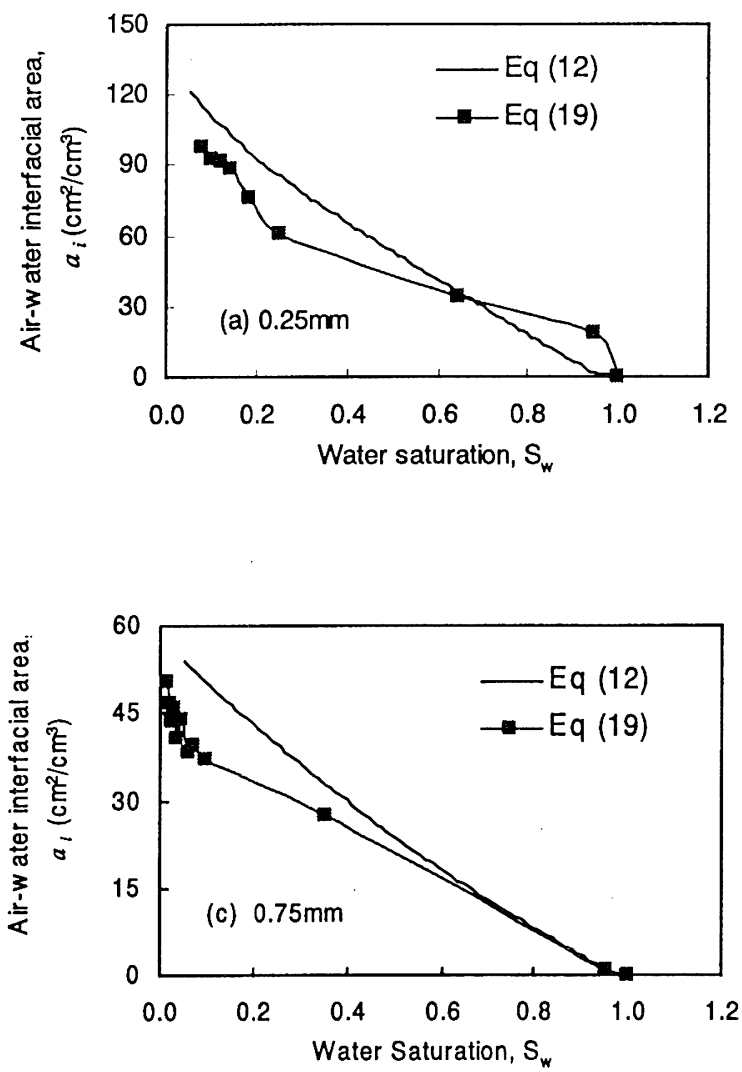

Fig. 8 Air-water interfacial area estimated by theoretical model (Eq. 12) and experimental method (Eq. 19) for different glass beads media. method is developed simplifying the complex network of the pore structure. Though the cross section of pore was taken as any shape, but the vertical length was assumed straight and equal to the length of the porous medium. But in reality, pores are tortuous rather than straight. As a result, the area calculated by summing the specific areas of all drained pores may provide overestimation. Moreover, theoretical model considers all the drained pores are empty lined with thin liquid film. But in reality, there might be some dead pores filled with liquid that were also taken into account for calculating air-liquid interfacial area, which provides overestimation of ai in theoretical method. But in the experimental process, the medium was made unsaturated from saturated condition with recycled surfactant solution, as a result, the surfactant monomers was

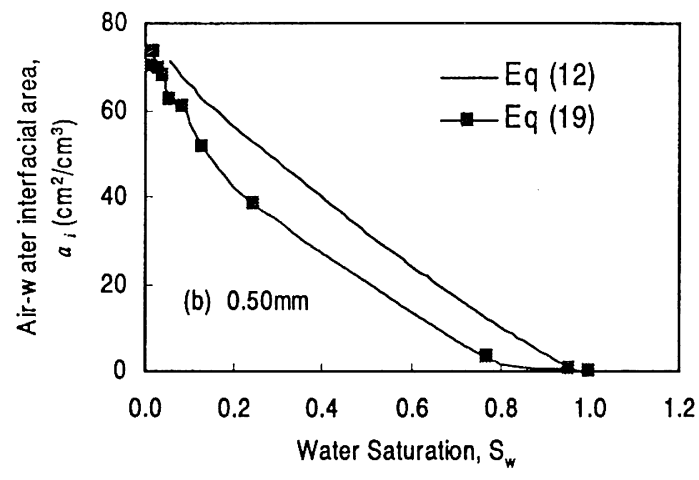


able to trace and adsorbed at the entire air-water interface. Thus, mass estimated for adsorbed surfactant at the air-water interface provides better estimation of $a_{i}$ in the experimental process.

Air-water interfacial area for $S_{w}=0$, extrapolated from the plot in Fig. 8 can be compared with the solid specific surface area $\left(a_{0}\right)$ calculated by conventional method (Dullien, 1979) on the assumption that all particles are perfect spheres and identical in size and are shown in Table 2. Results presented in Table 2 show that the $a_{i}$ for zero saturation obtained experimentally was much closer to the $a_{0}$. But $a_{i}$ found by this theoretical method shows a little bit overestimation for larger grain size media. This may be explained in the following way:

$\psi-\theta$ curve is usually asymptotic in the residual saturation zone. Air-water interfacial area calculated from $\psi-\theta$ curve also should show the same nature in this region. On the other hand, larger grain size medium generally has larger diameter of pores. As the interfacial area is calculated by summing the specific areas of the drain pores, it may provide overestimation for the larger grain size medium (Table 2).
The shape of the experimental results also shows some differences in nature with respect to grain size, especially above $S_{w}>0.4$. This may be the difference in pore distribution inside the medium. Difference in the nature of the pore structure in different grain size medium may arise from the difference in the degree of packing of the glass beads. Moreover, the number of experimental data points, obtained for $S_{w}>0.4>0.4$, was ery few because of the ring length used for the column construction. The ring was $3 \mathrm{~cm}$ in length. As a result, the experimental data points were obtained for every $3 \mathrm{~cm}$ height of the suction head. Thus, the data points, for air-water interfacial area above $S_{w}>0.4$, also became less and the shape for different grain size found different in this region of saturation.

\subsubsection{Comparison with Interfacial Tracer Technique (Kim et al., 1997)}

Kim et al., (1997) introduced a method named as interfacial tracer technique in order to estimate air-water interfacial area in unsaturated porous media. This technique was also developed under the consideration of surfactant adsorption concept. Miscible displacement ex-

Table 2 Comparison of air-water interfacial area for zero saturation obtained theoretically (Eq. 12) with that of experimentally found results (Eq. 19) and solid surface area for different porous media.

$\begin{array}{ccc}\text { Glass beads } & \text { Air-water interfacial area } a_{i}\left(\mathrm{~cm}^{2} / \mathrm{cm}^{3}\right) & \text { Specific solid surface } \\ \text { medium } & \left(\text { at } S_{w}=0\right) & \operatorname{area}^{2}, a_{0}\left(\mathrm{~cm}^{2} / \mathrm{cm}^{3}\right)\end{array}$

Eq (12) Eq. (19)

$\begin{array}{llll}0.25 \mathrm{~mm} & 138 & 120 & 148\end{array}$

$\begin{array}{llll}0.50 \mathrm{~mm} & 80 & 75 & 76\end{array}$

$\begin{array}{llll}0.75 \mathrm{~mm} & 60 & 50 & 51\end{array}$

${ }^{1}$ calculated from the extrapolation of the plot from Figure 8;

${ }^{2}$ calculated as described by Dullien (1979). 
periments were carried out in a sand mixture $\left(d_{50}=0.25 \mathrm{~mm}\right)$ using SDBS as reactive and $\mathrm{NaCl}$ as non-reactive tracers. Reactive solute was retarded due to the adsorption at the liquid/solid and air/liquid interfaces in the unsaturated porous media. SDBS adsorption at the solid surface was determined under water saturated conditions (i.e., no air/liquid inter face) in miscible displacements as described previously (for estimating MS in $§ 4.2 .1$ ). Using this adsorption onto solid matrix for each unsaturated case, air-water interfacial area was calculated by comparing the breakthrough curves (BTCs) obtained for reactive and non-reactive tracers for a constant water saturation, $S_{w}$ in each miscible displacement experiments. Basic concept between the surfactant mass extraction technique and Kim, et al., (1997)'s technique are same (i.e., surfactant adsorption concept). But the methodology in estimating air-liquid interfacial area for unsaturated porous media is completely different in these two experimental methods. Kim, et al., (1997) uses the surfactant adsorption at the air-liquid interface under dynamic conditions, but surfactant mass extraction technique uses the surfactant adsorption at the air-water interface under static condition while estimating the air-liquid interfacial area for unsaturated porous media. Kim, et al., (1997)'s method uses the miscible displacement for both saturated and unsaturated conditions. But in surfactant mass extraction technique, only miscible displacement experiment was carried out in water saturated conditions to estimate the surfactant mass adsorption onto solid phase $\left(M_{s}\right)$. The process described in surfactant mass extraction technique to estimate the air-liquid interfacial area for unsaturated porous media is a new method $(\S 4$. 2.1). However, some of the limitations found in Kim et al., (1997)'s method could be overcome by surfactant mass extraction technique.

Results found by this interfacial tracer technique and theoretical model (Eq. 12) for the sand mixture are shown in Fig. 9. Here it can be seen that the air-water interfacial area found by equation (12) was much higher than the experimental results. Kim et al., (1997) called the estimated air-water interfacial area as effective interfacial area because interfacial tracer could not access to all the interfaces between the air and water, especially in the lower water saturation during the miscible displacements. This gave an under estimation of air-water interfacial area by the interfacial tracer technique. Moreover, the system was considered as steady though it was not because of surface tension reduction during miscible displacements. These limitations could be overcome by the surfactant mass extrac. tion technique as described in earlier section (§4.2.1).

However, the experimental and the theoretical results were fitted linearly (Fig. 9) and air-water interfacial area for zero saturation was evaluated and shown in Table 3 together with the specific solid surface area for the sand mix. ture used. It appears that the area calculated by this theoretical method was higher than the experimental technique but closer to the solid sur. face area, which provides the validity of the method.

It has been seen that the theoretical method described in this study is able to provide some numerical insight to the problem without doing

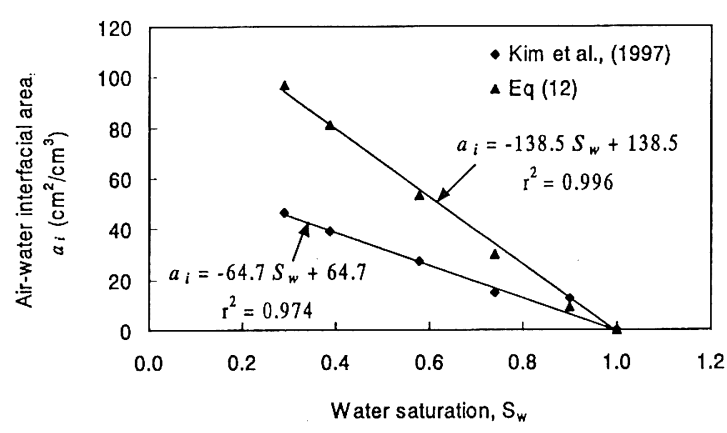

Fig. 9 Comparison of air-water interfacial area estimated by theoretical model (Eq. 12) and Kim et al., (1997). 
Table 3 Comparison of air-water interfacial area for zero saturation between the results obtained theoretically (Eq. 12) and experimentally by Kim et al. (1997) and with that of solid surface area for a sand mixture.

\begin{tabular}{|c|c|c|}
\hline \multirow[t]{2}{*}{ Sand mixture } & $\begin{array}{c}\text { Air-water interfacial area }{ }^{1}, a_{i}\left(\mathrm{~cm}^{2} / \mathrm{cm}^{3}\right) \\
\left(\text { at } S_{w}=0\right)\end{array}$ & \multirow[t]{2}{*}{$\begin{array}{l}\text { Specific solid surface } \\
\text { area }^{2}, a_{0}\left(\mathrm{~cm}^{2} / \mathrm{cm}^{3}\right)\end{array}$} \\
\hline & Kim et al., (1997) & \\
\hline $\mathrm{d}_{50}=0.25 \mathrm{~mm}$ & 139 & 180 \\
\hline
\end{tabular}

${ }^{2}$ from Kim et al., (1997).

any big experimental effort. Moreover, the method needs only drainage $\psi-\theta$ curve that can be obtained very easily for a specific porous media. The theoretical method developed in this paper to estimate air-liquid interfacial area was based only on the primary drainage soil characteristic curve. For secondary drainage and imbibition process, some modification may be needed in deriving the expression for air-liquid interfacial area. Some other factors like, tortuosity or ink-bottle effect may be taken into consideration, which actually affect the hysteresis of the system. However, future investigation may be conducted towards this direction.

\section{Conclusions}

A theoretical method was developed in order to quantify air-liquid interfacial area $\left(a_{i}\right)$, a fundamental hydrologic parameter, that describes the status of two immiscible fluids (i.e. air and a liquid) in soils and aquifer. The method was derived using soil characteristics curve or $\psi-\theta$ curve by introducing the term "hydraulic radius" for the pores inside the medium. This term was considered to abolish the effect of any shape of the pores. The derivation became a simple expres. sion that needs only drainage soil characteristics curve. $\psi-\theta$ curve for three different glass beads media were established experimentally using a column composed of several rings which allowed measuring the moisture content in each ring gravimetrically. The method was applied to estimate $a_{i}$ from these established $\psi-\theta$ curve and found that the results follow the general concept of decreasing $a_{i}$ with increasing liquid saturation. The results also show that air-liquid interfacial area was increasing with decreasing grain size, which actually reflects the frequency distribution of the pore sizes inside the porous media.

Air-liquid interfacial areas estimated by this theoretical model for three glass beads media were compared with the results obtained from an experimental method, which uses surfactant mass extraction technique. Comparison of the results shows that this theoretical method provides reasonable estimation of $a_{i}$ in unsaturated porous media. The results of $a_{i}$ at zero saturation were also compared with that of the specific solid surface area and found to be in good agreement. Theoretical method was also applied to determine $a_{i}$ on a sand mixture and compared with the experimental results obtained by interfacial tracer technique as used by Kim et al., (1997). Comparison of the results for zero saturation with the specific solid surface area revealed that the calculation of $a_{i}$ by this theoretical model provide 
reasonable estimation than the interfacial tracer technique.

Thus the method described in this paper was said to be adequate that can provide some quantitative information about the pore scale distribution of air and liquid inside the porous media without performing any big experiments.

\section{Notation}

List of symbols used.

\begin{tabular}{|c|c|c|}
\hline Symbol & Description & Unit \\
\hline$a_{i}$ & $\begin{array}{l}\text { air (or gas)-liquid interfacial area } \\
\text { per unit volume of porous medium }\end{array}$ & $\left(\mathrm{cm}^{2} / \mathrm{cm}^{3}\right)$ \\
\hline$D$ & pore diameter & $(\mathrm{cm})$ \\
\hline$r^{\prime}$ & density of liquid & $\left(\mathrm{g} / \mathrm{cm}^{3}\right)$ \\
\hline$g$ & acceleration due to gravity & $\left(\mathrm{cm} / \mathrm{sec}^{2}\right)$ \\
\hline$\sigma$ & surface tension of the liquid & $(\mathrm{dyn} / \mathrm{cm})$ \\
\hline 0 & volumetric liquid content & $\left(\mathrm{cm}^{3} / \mathrm{cm}^{3}\right)$ \\
\hline$\theta_{k}$ & volumetric gas content & $\left(\mathrm{cm}^{3} / \mathrm{cm}^{3}\right)$ \\
\hline$\phi$, & total porosity of the medium & $(-)$ \\
\hline$V_{k}$ & gas volume in the porous medium & $\left(\mathrm{cm}^{3}\right)$ \\
\hline$V_{1}$ & liquid volume in the porous medium & $\left(\mathrm{cm}^{3}\right)$ \\
\hline$V_{r}$ & void volume in the porous medium & $\left(\mathrm{cm}^{3}\right)$ \\
\hline$V_{1}$ & total volume of the porous medium & $\left(\mathrm{cm}^{3}\right)$ \\
\hline$d \theta_{k}$ & incremental gas content & $\left(\mathrm{cm}^{3} / \mathrm{cm}^{3}\right)$ \\
\hline$d N$ & $\begin{array}{l}\text { the number of pores in each incre- } \\
\text { ment of } d \theta_{k}\end{array}$ & $(-)$ \\
\hline$V_{1}$ & volume of a single drained pore & $\left(\mathrm{cm}^{3}\right)$ \\
\hline$a_{s}$ & surface area of a single pore & $\left(\mathrm{cm}^{2}\right)$ \\
\hline$R$ & hydraulic radius of the pore & $(\mathrm{cm})$ \\
\hline$A_{p}$ & $\begin{array}{l}\text { cross sectional area of pore of any } \\
\text { shape }\end{array}$ & $\left(\mathrm{cm}^{2}\right)$ \\
\hline$V_{m}$ & volume of liquid in the meniscus & $\left(\mathrm{cm}^{3}\right)$ \\
\hline$P$ & wetted perimeter of the pore & $(\mathrm{cm})$ \\
\hline$d A_{s}$ & surface area corresponding to the & \\
\hline$\psi$ & $\begin{array}{l}\text { incremental gas content } d \theta_{R^{*}} \\
\text { suction head of liquid }\end{array}$ & $\begin{array}{l}(\mathrm{cm}) \\
(\mathrm{cm})\end{array}$ \\
\hline$d_{\text {जN }}$ & average grain diameter & $(\mathrm{mm})$ \\
\hline$d \psi$ & $\begin{array}{l}\text { incremental suction head corres- } \\
\text { ponding to } d O_{k}\end{array}$ & $(\mathrm{~cm})$ \\
\hline$C_{\mathrm{s}}$ & concentration of surfactant solution & $\left(\mathrm{mol} / \mathrm{cm}^{3}\right)$ \\
\hline$M_{T}$ & $\begin{array}{l}\text { total surfactant mass per unit } \\
\text { volume }\end{array}$ & $\left(\mathrm{mol} / \mathrm{cm}^{3}\right)$ \\
\hline$M_{s}$ & $\begin{array}{l}\text { surfactant mass adsorbed at } \\
\text { solid/liquid interface }\end{array}$ & $\left(\mathrm{mol} / \mathrm{cm}^{3}\right)$ \\
\hline
\end{tabular}

$M_{l} \quad$ surfactant mass adsorbed at air/liquid interface $\left(\mathrm{mol} / \mathrm{cm}^{3}\right)$

$M_{l} \quad$ surfactant mass in the bulk liquid phase $\quad\left(\mathrm{mol} / \mathrm{cm}^{3}\right)$

$v_{w} \quad$ pore water velocity $(\mathrm{cm} / \mathrm{min})$

$D_{w} \quad$ hydrodynamic dispersion coefficient $\left(\mathrm{cm}^{2} / \mathrm{min}\right)$

$\rho_{b} \quad$ bulk density of the medium $\quad\left(\mathrm{g} / \mathrm{cm}^{3}\right)$

$k_{d} \quad$ linear distribution coefficient for surfactant adsorption on solid phase $\left(\mathrm{cm}^{3} / \mathrm{g}\right)$

$R_{1} \quad$ retardation factor (-)

$\Gamma \quad$ surface (excess) concentration of the surfactant $\left(\mathrm{mol} / \mathrm{cm}^{2}\right)$

$\theta_{w} \quad$ volumetric water content $\left(\mathrm{cm}^{3} / \mathrm{cm}^{3}\right)$

$a_{0}$ solid surface area $\quad\left(\mathrm{cm}^{2} / \mathrm{cm}^{3}\right)$

$S_{u} \quad$ water saturation $(-)$

$T$ absolute temperature (" $K$ )

$R \quad$ ideal gas constant $\left(8314 \mathrm{~J} \mathrm{kmol}^{-1} K^{-1}\right)$

$\S \quad$ section number

\section{Acknowledgment}

The authors are greatly indebted to the reviewers of editing committee, J. of Groundwater Hydrology for their valuable time spent on reviewing this paper, for correcting the inconsistencies and professional suggestions and comments, which improved the content of this paper.

\section{References}

Bear, J. and A. Verruijt (1987): Modeling gronndwater flow and pollution. D. Reidel, Tokyo, 414p.

Bradford, S. A. and F. J. Leij (1997): Estimating interfacial areas for multi-fluid soil systems. J. of Contaminant Hydrology, 27, 83-105.

Braida, W. J. and S. K. Ong (1998): Air sparging: Air-water mass transfer coefficients. Water Resources Research, 34 (12), 3245-3253.

Brewer, P. I., (1972): The determination of oil-soluble sulphonates by two-phase titration. Joumal of Institute of Petroleum, 58 (559), 41-46.

Brooks, R. H. and A. T. Corey (1966): Properties of porous media affecting fluid flow. J. of irrigation and drainage division, ASCE, June, IR 2, 61-88.

Campbell, G. S. (1974): A simple method for deter- 
mining unsaturated conductivity from moisture retention data. Soil Science, 117(6), 311-314.

Cary, J. W. (1994): Estimating the surface area of fluid phase interfaces in porous media. J. of Contaminant Hydrology, 15, 243-248.

Celia, M. A., W. G. Gray, C. D. Montemagno, and P. C.Reeves (1998): On the inclusion of interfacial area in models of two-phase flow in porous media. Proc. of the GQ'98 conf. on Groundwater quality: Remediation and Protection, Tubingen, Germany. IAHS publication number: 250, 81-87.

Cho, H. J. and P. R. Jaffe (1990): The volatilization of organic compounds in unsaturated porous media during infiltration. $J$. of Contaminant Hydrology, 6, 387-410.

Davies, J. T. and E. K. Rideal (1961) Interfacial Phenomena. Academic, New York

Dullien, F. A. L. (1979): Porons media: Fluid transport and pore structure. Academic, New York, 396p.

Hofstee, C., J. H. Dane and W. E. Hill (1997): Three fluid retention in porous media involving water, PCE and air. J. Contaminant Hydrology, 25, 235-247.

Imhoff, P. T. and P. R. Jaffe (1994): Effect of liquid distribution on gas-water phase mass transfer in an unsaturated sand during infiltration. $J$. of Contaminant Hydrology, 16, 359-380.

Lenhard, R. J. and J. C. Parker (1987): Measurement and prediction of saturation-pressure relationships in three-phase porous media systems. I of Contaminant Hydrology, 1, 407-424.

Karkare, M. V. and T. Fort (1996): Determination of the air-water interfacial area in wet unsaturated porous media. Langmuir, 12, 2041-2044.

Kawanishi, T., W. Hayashi, P. V. Roberts and M. J. Blunt (1998): Fluid-fluid interfacial area during two and three phase fluid displacement in porous media: A network model study. Proc. of the GQ'98 conf. on Gronndwater quality: Remediation and Protection, Tubingen, Germany. IAHS publication number: 250 , 89-96.

Kim, H., P. S. C. Rao and M. D. Annable (1997): Determination of effective air-water interfacial area in par- tially saturated porous media using surfactant adsorption. Water Resources Research, 33(12), 2705-2711.

Matsubayashi, U., R. M. T. Tanhueco, L. P. Devkota and F. Takagi (1995): On the electrode probes designed for the specific electrical conductance of unsaturated soil. J. Hydroscience and Hydraulic Engineering, $13(1), 81-95$.

Miller, C. T., M. M. Poirier-McNeill and A. S. Mayer (1990): Dissolution of trapped nonaqueous phase liquids: Mass transfer characteristics. Water Reson ces Research, 26 (11), 2783-2796.

Reeves, P. C. and M. A. Celia (1996): A functional relationship between capillary pressure, saturation and interfacial area as revealed by a pore-scale network model. Water Resources Research, 32(8), 2345-2358.

Rosen, M. J. (1989): Surfactant and interfacial phenomena. John Wiley, New York, 436p.

Saripalli, K.P., H. Kim, P. S. C. Rao and M. D. Annable (1997): Measurement of specific fluid-fluid interfacial area of immiscible fluids in porous media. Environment Science and Technology, 31 (3), 932-936.

Skopp, J. (1985): Oxygen uptake and transport in soils: Analysis of the air-water interfacial area. Soil Science Society of America Jonrnal, 49 (6), 1327-1331.

Tanhueco, R. (1993): On the properties of electrodes probes in determining the specific electrical conduc. tance of the soil-water environment. M. Eng. Thesis, Department of Civil Engineering, Nagoya University, $27 \mathrm{p}$.

Van Genuchten, M. Th. (1980): A closed form equation for predicting the hydraulic conductivity of unsaturated soils. Soil Science Society of America Jonr. nal, 44, 892-898.

Wilkins, M. D., L. M. Abriola and K. D. Pennell (1995): An experimental investigation of rate-limited nonaqueous phase liquid volatilization in unsaturated porous media: steady state mass transfer. Water Resources Research, 31 (9), 2159-2172.

(受付：1999年 7 月 5 日、受理：2000年 4 月 8 日) 